\title{
Modeling of a Railway Sanding System Using Vibration Fluidization
}

\author{
Y.P. Bulavin ${ }^{1}$ and P.Y. Konovalov ${ }^{1,}{ }^{*}$ \\ ${ }^{1}$ Rostov state transport University, Sq. Rostovskogo Strelkovogo Polka Narodnogo opolchenya, 2, \\ Rostov-on-Don, Russian Federation
}

\begin{abstract}
The model of the sand distributor of the sand feeding system of traction rolling stock, the operation of which is based on the effect of vibration fluidization of sand, has been considered. A pneumatic pulsator was used as a source of vibration impact. Experimental studies have shown that this design allows for a continuous regulated supply of sand. The power of the sand distributor membrane vibrations at the disturbing frequency can be used as a criterion characterizing the impact of the pulsator on the sand. There is a close to linear dependence of the sand flow rate on the power of vibrations.
\end{abstract}

\section{Introduction}

The authors' works show that in order to increase the coupling properties of traction rolling stock, it is advisable to provide a continuous sand delivery to the wheel-rail contact area [1$3]$. It is necessary to ensure the system performance not only as a mass flow rate per unit of time, but also as a mass flow rate per running meter of the track [4-7]. In addition, the sand feeding system must be controlled by the mass flow rate of sand. In the work [8], the authors showed that a continuous and controlled sand delivery can be provided using the effect of vibration fluidization. The installation used in [8] made it possible to identify the main regularities of sand fluidization [9] and qualitatively investigate the process, but it does not allow us to evaluate the technical implementation of the sand distributor of the sand feeding system.

In this paper, we will perform a physical simulation of the operation of a prototype sand distributor using the effect of vibration fluidization. To excite vibrations, we will use compressed air, since this is a common resource on traction rolling stock and existing sand feeding systems use it.

\section{Methods}

A laboratory installation of a prototype sand distributor has been developed to simulate a continuous dosed sand delivery. The installation diagram is shown in Figure 1.

* Corresponding author: pashafromru@yandex.ru 


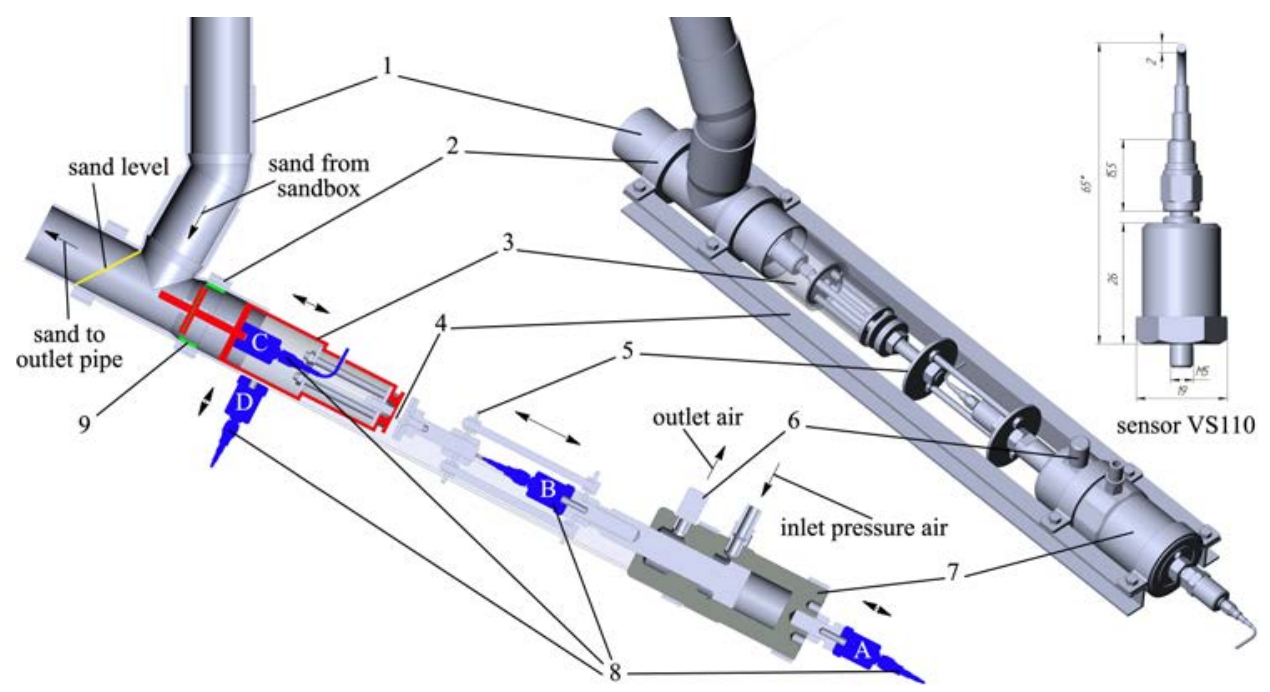

Fig. 1. Laboratory installation: 1 Simulation model of the cavity of the sand distributor; 2 Clamp; 3 Elongated piston; 4 Guide frame; 5 Elongated rod; 6 Muffler; 7 Pneumatic vibration pulsator; 8 Vibration sensor VS110; 9 Membrane with locking ring

The laboratory installation is a complex that combines driving, measuring and regulating devices.

Air compressor;

Pressure reducing valve;

Disconnecting ball valve;

Pneumatic single-acting piston vibrating pulsator FAL-18;

Model of the cavity of the sand distributor;

Frame with a variable angle of inclination;

The VS110 piezoelectric accelerometer with a built-in preamplifier of the ICP/IEPE standard (registered in the State Register of Measuring Instruments No. 44939-10);

Spectrum Analyzer ZET 038;

Software for recording acceleration sensor readings;

Industrial Notebook;

Electronic scales;

Container for receiving sand;

Digital level.

The source of compressed air is a compressor with a receiver with a volume of 50 liters, a flow rate of up to $350 \mathrm{l} / \mathrm{min}$ at a maximum pressure of 8 bar. The compressed air generated is supplied from the compressor unit to the pneumatic vibration pulsator FAL-18 through a pressure reducing valve and a disconnecting ball valve. This pneumatic actuator 7 is a piston pneumatic pulsator of linear movements with wide possibilities of regulating the frequency and the amplitude of the rod movement in the operating pressure range from 1 to 6 bar (the parameters of FAL-18 are presented in table 1).

Table 1. Technical data of pneumatic piston vibrator FAL-18

\begin{tabular}{ccccc}
\hline Pressure, bar & Frequency, $\mathbf{~ m i n}^{\mathbf{1}}$ & Force, $\mathbf{N}$ & Moment, cmkg & Air consumption, 1/min \\
\hline 2 & 1420 & 60 & 0.45 & 20 \\
4 & 1900 & 140 & 0.54 & 40 \\
6 & 2250 & 205 & 0.54 & 60 \\
\hline
\end{tabular}


For fixing the vibration sensors, an elongated piston 3 and a rod of the vibration drive 5 with mounting pads located on them were designed. With the help of the developed design of the installation, it became possible to place four piezoelectric vibration sensors of accelerations 8 , which made it possible to make the necessary measurements. The sensors are conventionally labeled A, B, C and D (figure 1), depending on their location; so A is fixed at the end surface of the vibration drive 7, B is on the rod 5 of the pulsator $7, \mathrm{C}$ in the elongated piston 3 is directly rigidly connected through the stud M5 to the part of the piston on the latex membrane 9, which is in contact with sand particles, and the sensor D is mounted on the frame 4 orthogonally to the previous three. Installing the D sensor is related to the specific characteristics of the VS 110 series accelerometers, which can only make measurements in one plane. The main parameters of the vibration sensors are given in table 2.

The VS110 piezoelectric accelerometers have a built-in preamplifier of the ICP/IEPE standard, which allows them to be directly connected to the ZET 038 spectrum analyzer, which is compatible with an Industrial Notebook. The software and the ZetLab analyzer unit allow connecting up to 8 sensors simultaneously. This complex is certified in the State Register of Measuring Instruments. The connection diagram of the vibration sensors is shown in figure 2. The TEDS technology for surveying accelerometers allows the spectrum analyzer to automatically determine the type of sensor and its sensitivity using Electronic Data Sheets for sensors.

Table 2. Technical specifications of the piezoelectric accelerometer VS 110

\begin{tabular}{|l|c|}
\hline \multicolumn{1}{|c|}{ Parameter } & Value \\
\hline Sensitivity & $100 \mathrm{MB} / \mathrm{g}$ \\
\hline Frequency range & $0.5 \ldots 10000 \mathrm{~Hz}$ \\
\hline Relative transverse sensitivity & $\leq 5 \%$ \\
\hline Amplitude range & $\pm 50 \mathrm{~g}$ \\
\hline Self-noise, RMS & $<0.5 \mathrm{mg}$ \\
\hline Weight & $30 \mathrm{\Gamma}$ \\
\hline
\end{tabular}

\section{vibration sensors VS110}

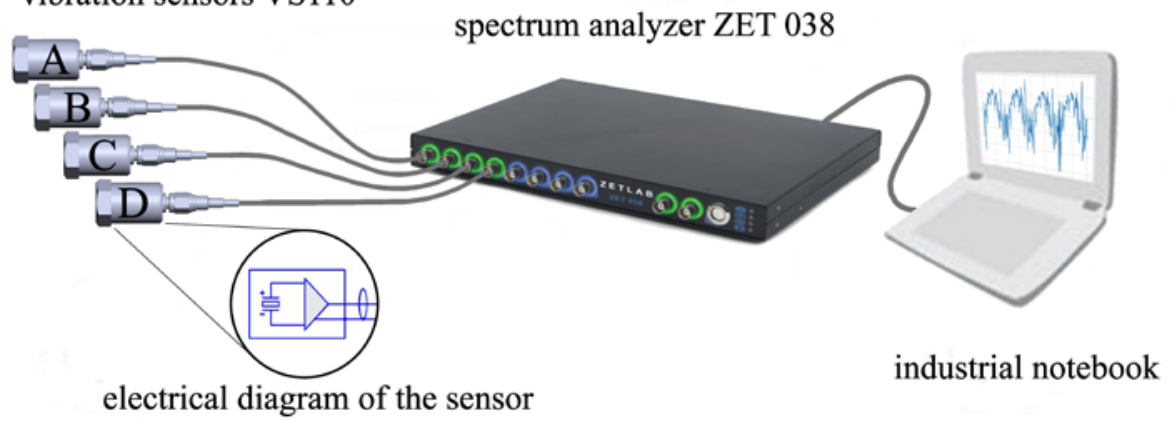

Fig. 2. Connection diagram of the measuring complex

To conduct the experiment, the model is installed at a certain angle to the horizontal plane, which is typical for existing sand distributors. By varying the pressure in the pulsator, we can change the frequency of vibrations. 


\section{Results}

As a result of the experiment, the values of the vibration frequency of the membrane and the sand flow rate have been determined, which are shown in table 3.

Table 3. Results of the experiment to determine the sand flow rate depending on the vibration value of the pneumatic vibration pulsator

\begin{tabular}{|c|c|c|}
\hline Air pressure, bar & Sand mass netto, grams & Frequency, hertz \\
\hline 1 & 16 & 18.5535536 \\
\hline 1.5 & 39 & 19.5295295 \\
\hline 2 & 392 & 20.005005 \\
\hline 3 & 411 & 22.4574575 \\
\hline 4 & 638 & 24.6596597 \\
\hline 5 & 970 & 27.3373373 \\
\hline 6 & 1055 & 30.015015 \\
\hline
\end{tabular}

Recording accelerations from sensors allows us to consider in detail the processes during the operation of the prototype sand distributor. Figure 3 shows spectrograms of membrane accelerations at a pulsator pressure of 5 bar.
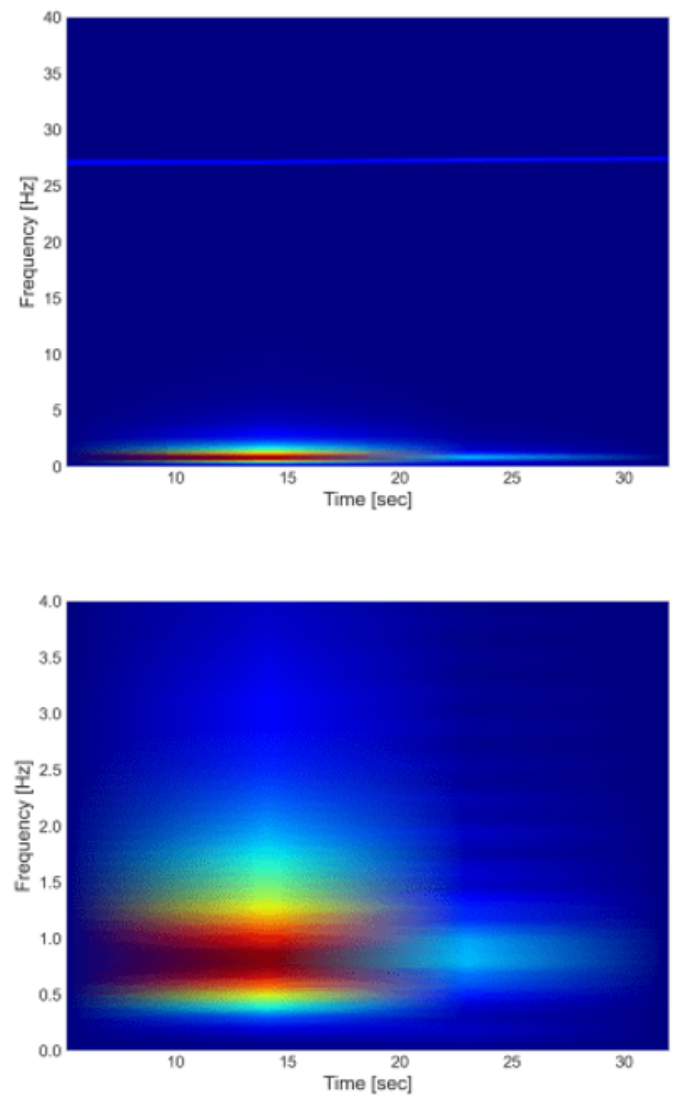

Fig. 3. Spectrograms of membrane accelerations at a pressure of 5 bar 
Non-stationary vibrations of sand in the sand distributor with frequencies up to $2 \mathrm{~Hz}$ are observed, which continue with different frequencies all the time of the experiment.

The power spectra of the accelerations of the membrane and the pulsator rod are shown in figure 4.
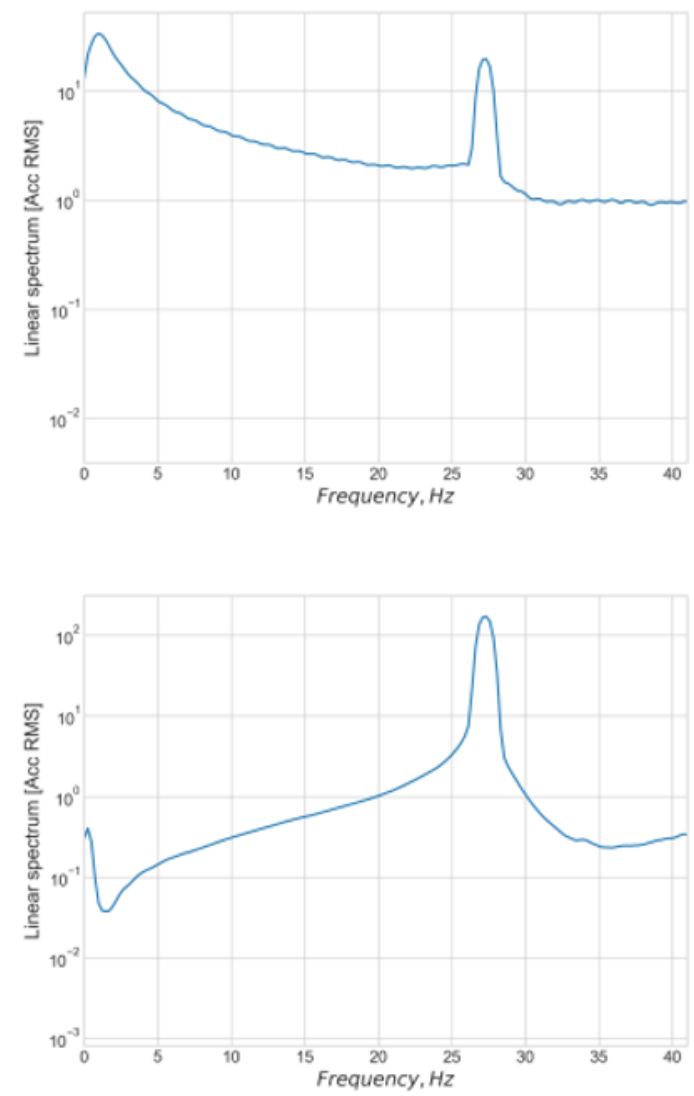

Fig. 4. Power spectra of the accelerations of the sand distributor membrane and the pulsator rod at a pressure of 5 bar

It follows from the graphs that vibrations at low frequencies are not caused by lowfrequency vibrations of the rod.

The flow rate of sand from the cavity of the sand distributor model depends on the vibration frequency of the vibration drive, the pressure in the pulsator, the power of the membrane vibrations. The flow rate depending on the specified parameters is represented on the graph of figure 5 


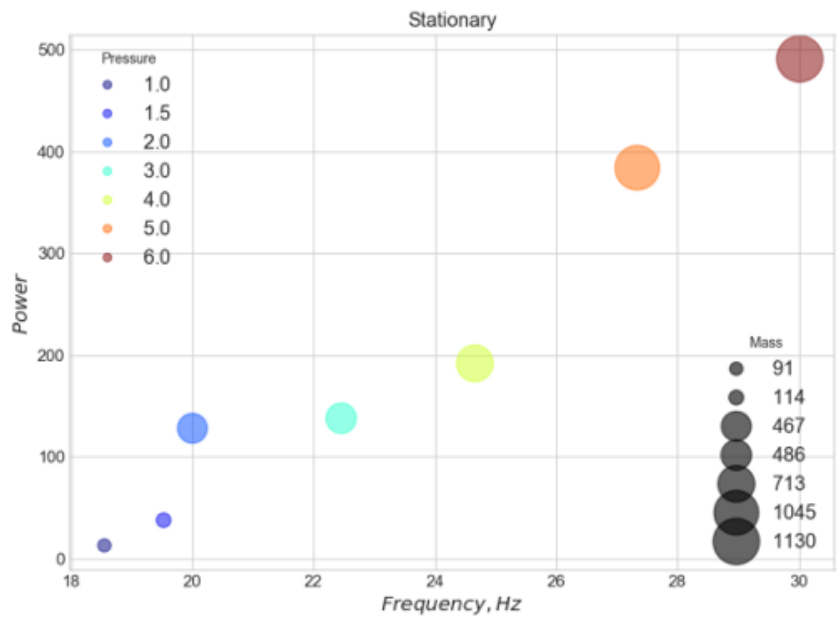

Fig. 5. Mass flow rate of sand in the sand distributor model

\section{Discussion}

The sand distributor model in this experiment provides the possibility of impact on the membrane, which favorably affects the operation of the system when, for some reason, the sand is excessively compacted. For example, under operating conditions, such compaction can be caused by moistening or partial freezing of sand.

At pressures in the pulsator of more than 3 bar, the vibration impact on the sand can be accompanied by vibrations of the sand at low frequencies. This phenomenon, in the first approximation, can be described by representing the sand as a solid body that moves in the sand distributor under the action of a force from the membrane; such a model was considered in [8]. It should be noted that the force impact of the pulsator with a pressure of 3 bar is enough to ensure the sand exit from the sand distributor under any loading conditions, and this value can be considered the lower limit from which controlling the continuous supply of sand should be started.

The use of a pneumatic pulsator for vibration fluidization imposes its own features on the operation of the model, which will also appear in real conditions. First of all, in this experiment, such a feature is the control of the vibration frequency and the impact force of the rod by means of the pressure in the pulsator. As experiments have shown, it is preferable to implement independent control here.

In view of the above-mentioned control feature, special attention should be paid to the criterion by which the control effect is monitored. In the work, the dependences of the flow rate on the frequency and the power of vibrations at this frequency are presented in figure 5, and if we have almost the same flow rate at the frequencies of $20 \mathrm{~Hz}$ and $22.5 \mathrm{~Hz}$ and the impression is created that the system is insensitive to frequency changes, then, looking at the power, we can see that it has not changed practically and correlates well with the flow rate.

\section{Conclusion}

In this paper, a model of the sand distributor of the sand feeding system of traction rolling stock has been considered, the operation of which is based on the effect of 
vibration fluidization of sand. A pneumatic pulsator is used as a source of vibration impact. Experimental studies have shown that this design allows for a continuous regulated delivery of sand. It is possible to use the power of the sand distributor membrane vibrations at the disturbing frequency as a criterion characterizing the impact of the pulsator on the sand. There is a close to linear dependence of the sand flow rate on the power of vibrations.

It is advisable to direct further research to identify the influence of external disturbances, simulating the movement of a locomotive, on the sand flow rate.

\section{References}

1. Bulavin, Y. P. Models of locomotive traction drives for the improvement of sand feeding system / Bulavin, Y. P., Konovalov, P. Y. and Volkov, I. V. IOP Conf. Series: Earth and Environmental Science (2021). 666 042089. DOI:10.1088/17551315/666/4/042089.

2. Konovalov, P. Yu. Improving the pneumatic system of sand supply of electric locomotives by introducing throttling devices with a servo drive / P. Yu. Konovalov // Vestnik RSUPS. - 2020. - No. 1. - P. 25-33. - ISSN 0201-727X.

3. Shapovalov, V. V. Metal Plating of Friction Surfaces of the "Wheel-Rail" Pair / Shapovalov, V. V., Migal, Y. F., Ozyabkin, A. L., Kolesnikov, I. V., Kornienko, R. A., Novikov, E. S., Feyzov, E. E. and Kharlamov, P. V. // Journal of Friction and Wear (2020). 41(4), 338-346. DOI:10.3103/s1068366620040121

4. Konovalov, P. Yu. Improvement of anti-slip properties of transport machines on the basis of modernization of the pneumatic drive of the sand system / P. Yu. Konovalov, Yu. P. Bulavin, I. V. Volkov // Vestnik RSUPS - 2021. - No. 1. - pp. 8-19. DOI: 10.46973/0201-727X_2021_1_8.

5. Luzhnov, Y. M. Nanotribology of wheel-rail coupling. Reality and possibilities / Y.M. Luzhnov // Moscow : Intext, 2009. - 176 p.

6. Kokhanovsky, V. A. A Lubricant for Rotaprint Lubrication of the Wheel-Rail System / Kokhanovsky, V. A. and Glazunov, D. V. // Journal of Friction and Wear (2020). 41(6), 531-537. DOI: 10.3103/S1068366620060100

7. Shapovalov, V. V. Improving the efficiency of the path - Rolling stock system based on the implementation of anisotropic frictional bonds / Shapovalov, V. V., Kolesnikov, V. I., Kharlamov, P. V., Kornienko, R. A., Petrik, A. M. // IOP Conference Series: Materials Science and Engineering (2020). 900(1), 1-5. DOI: 10.1088/1757-899X/900/1/012011

8. Konovalov, P. Y. Analysis of granular materials vibrorheology of a railway sanding system [Text] / Konovalov P. Y., Bulavin Y. P., Volkov I. V. // IOP Conference Series: Materials Science and Engineering. Volume 709(2), 2020. 033093. DOI:10.1088/1757-899X/709/3/033093

9. Blechman, I. I. Vibrational mechanics and vibrational rheology (theory and applications) / I. I. Blechman // Moscow : FIZMATLIT, 2018 - 752 p. - ISBN 978-59221-1750-0. 